The Brock Review Volume 10 (2008)

(C) Brock University

\title{
CALL FOR PARTICIPATION
}

\section{Call for Papers}

1) Special Issue: The Brock Review is seeking scholarly essays and creative works for a special issue dedicated to the theme, "Madness Manifest: Creativity, Art and the Margins of Mental Health." Possible topics might include:

-the relationship between creativity and madness

-madness and nature

-the politics of madness

-artistic explorations of madness/mental illness

-power and pathology

-representations of madness in performance, literature, popular culture

The publication of this issue will be thematically related to the "Madness Manifest" symposium hosted by the Department of Dramatic Arts at Brock University. Manuscripts and creative works should be submitted via the journal website by the 12th of December, 2008. Please see Author Guidelines section of the website for more details.

2) General Issues: The Brock Review is seeking scholarly essays and creative works for upcoming general issues. There is no specific deadline for general issues. To be considered for publication in The Brock Review, scholarly essays and creative works should be on topics relevant to Humanitiesbased research. For more details about the mandate of The Brock Review and for Author Guidelines, please see the journal website.

Scholarly essays submitted to The Brock Review should not exceed 25 double-spaced pages in length. Essays should adhere to the latest edition of the Chicago Manual of Style and include endnotes (where necessary) and a bibliography. Manuscripts should be original works and should not be published (or under consideration for publication) in another format. Each submission must be accompanied by a 100 word abstract, and a brief (2-3 line) biography of the author.

It is the sole responsibility of the author to obtain any necessary copyright permissions for images accompanying an essay. If your essay is accepted for publication, you must provide copies of these permissions before your essay can be published.

Creative work (i.e.: paintings, photographs, poetry, short fiction or other types of work suitable to the online format of the journal) will also be subject to peer-review and should be submitted in an electronic format via the journal website. In the event that your submission is too large of a file to submit online, CDs or DVDs can be sent to the journal editor at the address below. Creative work must be accompanied by a statement indicating the creator(s) of the piece have given consent to have it included in The Brock Review. 


\section{Call for Reviewers}

The Brock Review is currently accepting applications for peer-reviewers and for book reviewers. If you are interested in either of these positions, please contact the journal editor and outline your areas of interest and expertise.

\section{For Authors and Publishers}

If you have a book you think would be suitable for a book review in future issues of The Brock Review, please contact the journal editor.

\section{Contact Information}

Dr. Keri Cronin

Editor, The Brock Review

c/o Department of Visual Arts

The Marilyn I. Walker School of Fine \& Performing Arts

Brock University

500 Glenridge Ave.

St. Catharines, ON L2N 4C2

CANADA

Email: mailto:brockreview@brocku.ca

Website: http://www.brocku.ca/brockreview 